\title{
Efficacy of Cabozantinib in Metastatic Papillary Renal Cell Carcinoma Following Ineffective Treatment With Initial Therapy of Nivolumab and Ipilimumab
}

\author{
HIDEKAZU TACHIBANA, YUDAI ISHIYAMA, MAKI YOSHINO, \\ KAORI YAMASHITA, DAISUKE TOKI and TSUNENORI KONDO \\ Department of Urology, Tokyo Women's Medical University Medical Center East, Tokyo, Japan
}

\begin{abstract}
Sunitinib is listed as first-line therapy for non clear-cell renal cell carcinoma (RCC) in several guidelines. However, in the era of immunotherapy, there is an urgent need for updated evidence for the treatment of metastatic non clear-cell RCC. Herein, we present three cases of patients with type 2 papillary RCC who were effectively treated with cabozantinib. The first case was a 48-year-old woman who underwent radical nephrectomy (pT3aNOMO). The tumor relapsed in the retroperitoneum 3 months postoperatively and was unresponsive to first-line nivolumab plus ipilimumab (NI). After the use of cabozantinib, the tumors drastically shrunk in 2 weeks, and complete response was achieved 3 months later. The second case was a 55-year-old man who underwent radical nephrectomy (pT3aN2M1). Metastatic lesions continued to grow with first-line NI, and cabozantinib was used as the second-line therapy. All metastatic lesions had shrunk by 50\% after 4 months. The third case was a 36year-old man with multiple tumors in the left solitary kidney and iliopsoas muscle metastasis. First-line therapy with NI was ineffective; subsequently, second-line axitinib was used for 5 months, and the disease was identified as progressive. Cabozantinib was started as third-line therapy. Multiple tumors shrunk in 2 weeks. There is little evidence concerning the treatment of papillary RCC. We experienced low efficacy of NI for first-line treatment of papillary RCC for three patients who were subsequently effectively treated with
\end{abstract}

This article is freely accessible online.

Correspondence to: Hidekazu Tachibana, MD, Ph.D., Department of Urology, Tokyo Women's Medical University Medical Center East, 21-10 Nishiogu, Arakawa-ku, Tokyo 116-8567, Japan. Tel. +81 338101111, Fax: +81 338100705, e-mail: tachi6ana@yahoo.co.jp ORCID ID: Hidekazu Tachibana: 0000-0002-1977-9814

Key Words: Renal cell carcinoma; kidney cancer; immunotherapy; nivolumab; ipilimumab. cabozantinib. Cabozantinib inhibits multiple tyrosine kinase receptors, which may suppress aggressive tumor progression of type 2 papillary RCC. Cabozantinib or combination with immuno-oncological drugs may be a promising treatment option for papillary RCC.

Cabozantinib was shown to confer longer progression-free (PFS) and overall (OS) survival over everolimus as secondline treatment and longer PFS over sunitinib as initial treatment in patients with metastatic clear-cell renal cell carcinoma (ccRCC) $(1,2)$. However, the efficacy of cabozantinib in patients with papillary RCC (pRCC) remains unknown. Herein, we present three cases of patients with pRCC who were highly responsive to cabozantinib following ineffective initial therapy with nivolumab and ipilimumab.

\section{Case Reports}

Retrospective study's protocol of this report was approved by the appropriate Institutional Review Boards (2020-0009). Pathological diagnoses were made according to the 2016 World Health Organization classification (3). The best response during NI treatment was recorded with reference to the Response Evaluation Criteria in Solid Tumors (RECIST, version 1.1) (4).

The first case was a 48-year-old female patient with no medical history who presented with left lumbar pain, and a tumor was found in the left kidney. A contrast-enhanced computed tomographic scan showed a 13-cm left kidney mass with renal venous thrombus extension, with no regional lymph node involvement or metastatic disease. Open radical nephrectomy revealed pathological findings of type 2 pRCC, Fuhrman nuclear grade 2, and pT3aNOM0. Three months postoperatively, the tumor relapsed in the left retroperitoneum $(5 \mathrm{~mm})$ and inguinal lymph node $(17 \mathrm{~mm})$. Nivolumab plus ipilimumab therapy was started as the initial therapy for International Metastatic Renal Cell Carcinoma Database Consortium (IMDC) intermediate risk disease (5). 


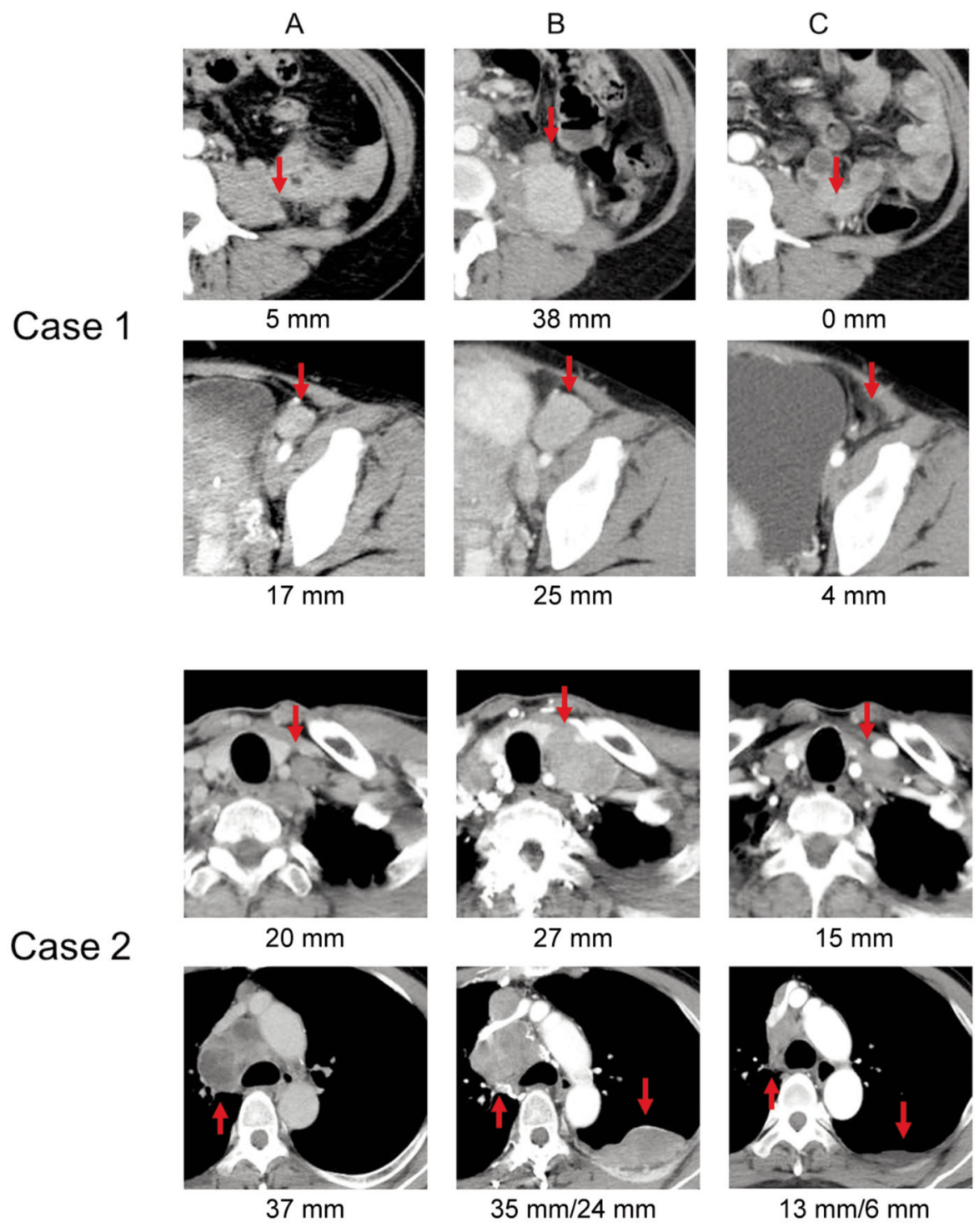

Figure 1. Tumor responses from the commencement of the first- to second-line treatment in two cases (contrast-enhanced computed tomography). Case 1, upper panel: metastasis in iliopsoas muscle; Iower panel: metastasis in inguinal lymph node. Case 2, upper panel: metastasis in the cervical lymph node; lower panel: metastasis in the mediastinal lymph node and in the pleura. A: Metastatic status at the start of nivolumab and ipilimumab therapy. B: Metastatic status at the evaluation of progressive disease with nivolumab and ipilimumab. C: Metastatic status showing the efficacy of cabozantinib after 3 months of therapy.

However, unresponsive to four cycles of nivolumab plus ipilimumab, the relapsed tumors enlarged in the retroperitoneum $(38 \mathrm{~mm})$ and inguinal lymph node $(25 \mathrm{~mm})$. As immune-related adverse events, grade 1 myalgia in the extremities was observed, which was relieved spontaneously. Cabozantinib (60 mg per day) was then started as secondline therapy. Two weeks later, the patient presented with a fever of $40^{\circ} \mathrm{C}$ without any other symptom, and computed tomography revealed drastic shrinkage of the relapsed tumors (retroperitoneum: $10 \mathrm{~mm}$; inguinal lymph node: 7 $\mathrm{mm}$ ) (Figure 1). Complete response was achieved 3.5 months later. Temporarily, drug interruption was necessary, and the dose was reduced to $20 \mathrm{mg}$ due to adverse events, including grade 4 neutropenia, grade 2 hypothyroidism, alopecia, and palmar-plantar erythrodysesthesia.

The second case was a 55-year-old male patient without past medical history who presented with left back pain and gross hematuria. Contrast-enhanced computed tomography showed a 14-cm left renal tumor with metastases of the mediastinal lymph nodes and vertebral bone that compressed his spinal cord. He underwent emergency decompressive surgery and radical nephrectomy. Pathological findings were type 2 pRCC, 
Table I. Individual clinical profiles in patients with papillary renal cell carcinoma treated with nivolumab plus ipilimumab as first-line therapy.

\begin{tabular}{|c|c|c|c|}
\hline \multirow[b]{2}{*}{ Characteristic } & \multicolumn{3}{|c|}{ Case } \\
\hline & 1 & 2 & 3 \\
\hline Age at the start of cabozantinib, years & 48 & 55 & 36 \\
\hline Gender & Female & Male & Male \\
\hline KPS & 100 & 100 & 100 \\
\hline Comorbidity & None & None & None \\
\hline IMDC risk classification & Intermediate & Intermediate & Poor \\
\hline No. of risk factors & 2 & 1 & 3 \\
\hline Prior nephrectomy & Done & Done & No \\
\hline Fuhrman grade & 2 & 2 & 4 \\
\hline No. of metastases & 2 & 3 & 3 \\
\hline Site of metastases & $\begin{array}{l}\text { Lymph node, } \\
\text { retroperitoneum }\end{array}$ & $\begin{array}{l}\text { Lung, lymph node, } \\
\text { bone }\end{array}$ & $\begin{array}{l}\text { Left kidney, lymph node, } \\
\text { iliopsoas muscle }\end{array}$ \\
\hline Adjuvant radiation therapy & No & Done & No \\
\hline Best objective response to first line therapy* & PD & $\mathrm{SD}$ & PD \\
\hline TTP on first-line therapy, months & 2.0 & 12.2 & 2.5 \\
\hline Pattern of PD* & Target lesion growth & $\begin{array}{l}\text { Target lesion growth } \\
\text { Appearance of new lesion }\end{array}$ & Target lesion growth \\
\hline Subsequent therapy & Cabozantinib & Cabozantinib & $\begin{array}{l}\text { Second line: Axitinib } \\
\text { TTP: } 5.9 \text { months } \\
\text { Best objective response: SD } \\
\text { Third line: Cabozantinib }\end{array}$ \\
\hline Initial dose of cabozantinib & $60 \mathrm{mg}$ & $60 \mathrm{mg}$ & $60 \mathrm{mg}$ \\
\hline Best objective response to cabozantinib* & $\mathrm{CR}$ & PR & PR \\
\hline Adverse events & $\begin{array}{c}\text { Neutropenia (grade 4) } \\
\text { Hypothyroidism (grade 2) } \\
\text { Alopecia (grade 1) } \\
\text { Peripheral edema (grade 1) } \\
\text { PPE (grade 1) } \\
\text { Diarrhea (grade 1) } \\
\text { Hoarseness (grade 1) }\end{array}$ & $\begin{array}{c}\text { Diarrhea (grade 2) } \\
\text { Hypothyroidism (grade 2) } \\
\text { Hypertension (grade 2) } \\
\text { PPE (grade 1) }\end{array}$ & Diarrhea (grade 2) \\
\hline Dose interruption/reduction & Interrupted and reduced to $20 \mathrm{mg}$ & No & No \\
\hline Follow-up after cabozantinib, months & 4.2 & 4.0 & 3.1 \\
\hline
\end{tabular}

KPS: Karnofsky performance status; IMDC: International Metastatic Renal Cell Carcinoma Database Consortium; PD: progressive disease; PPE: palmar-plantar erythrodysesthesia; TTP: time to progression. *According to the Response Evaluation Criteria in Solid Tumors guideline (4).

Fuhrman nuclear grade 2, and pT3aN2M1. Immediately after surgery, nivolumab and ipilimumab therapy was initiated for IMDC intermediate risk disease. The best tumor response was stable disease at 5 months. Radiation was added for new lesions, including vertebral and pelvic metastases. However, metastatic lesions continued to grow for another 7.2 months. Cabozantinib (60 mg per day) was then started as second-line therapy. All target lesions in the mediastinal lymph node, lung, and pleural metastases had shrunk by $50 \%$ after 4 months (Figure 1). He presented with grade 2 palmar-plantar erythrodysesthesia, hypothyroidism, and hypertension, which did not require drug interruption or dose reduction.

The third case was a 36-year-old male patient who had a past history of testicular cancer (seminoma). He underwent right radical nephrectomy due to right $\mathrm{RCC}$ at the age of 28 years (pRCC, pT2aN0M0, Fuhrman nuclear grade 4). Additionally, a $2.7-\mathrm{cm}$ left renal tumor appeared at the age of
35 years, and he underwent open partial nephrectomy. However, multiple recurrent tumors in the left kidney (5.5$6.2 \mathrm{~cm})$ and iliopsoas muscle $(2.3 \mathrm{~cm})$ were found 9 months later. The tumors were unresponsive to initial therapy with nivolumab and ipilimumab. Subsequently, axitinib was used for 5 months, and the best tumor response was stable disease. Cabozantinib (60 mg per day) was then used as third-line therapy, and the tumor drastically shrank in 2 weeks, with the patient having a fever of $39^{\circ} \mathrm{C}$ (Table I). Grade 2 diarrhea was identified as an adverse event in these 2 weeks. However, drug interruption or dose reduction was not necessary.

\section{Discussion}

Currently, sunitinib is listed as first-line therapy for non-ccRCC in the National Comprehensive Cancer Network guidelines (6). However, due to their aggressive nature and poor response to 
targeted agents, type 2 pRCC subtypes have been reported to have a worse prognosis compared with ccRCC (7). Nivolumab and ipilimumab therapy was reported to lead to longer PFS and OS compared with sunitinib in patients with IMDC intermediate- and poor-risk ccRCC in CheckMate 214 (8). All our patients were young and did not have serious comorbidities. Therefore, we chose nivolumab plus ipilimumab and expected a high rate of complete response for type 2 pRCC. Unfortunately, all patients had progressive disease on this first-line nivolumab and ipilimumab therapy. Our recent report also showed modest efficacy of nivolumab and ipilimumab therapy in cases of pRCC; one out of seven patients achieved partial response, and five patients had progressive disease (9). Therefore, another treatment option for pRCC is needed. Here, we reported three cases that were effectively treated with second- or third-line therapy using cabozantinib after failure of first-line immunotherapy.

Cabozantinib inhibits multiple tyrosine kinase receptors associated with tumor progression, including vascular endothelial growth factor, mesenchymal-epithelial transition (MET), rearranged during transfection, and anexelekto (RET) (10). Martinez et al. reported the efficacy of cabozantinib in non-ccRCC in a multicenter retrospective analysis and concluded that cabozantinib was effective in controlling nonccRCC (11). To the best of our knowledge, this is the first report of the efficacy of cabozantinib after nivolumab and ipilimumab in cases of pRCC. Choueiri et al. reported the efficacy of savolitinib (a selective MET inhibitor) against MET-driven pRCC in a phase III trial. The PFS, objective response rate, and OS were greater with savolitinib compared with those with sunitinib, and they concluded that a combination therapy with immuno-oncological drugs was promising (12). The efficacy of cabozantinib in our three cases may be due to its ability to inhibit many receptors. Furthermore, there is a possibility of a synergistic effect of cabozantinib with first-line immuno-oncological drugs; the ongoing clinical trial on nivolumab and cabozantinib (NCT03141177) may show this to be a promising regimen for pRCC. There are few reports about pRCC; however, cabozantinib or a combination of cabozantinib and immunooncological drugs may be a hopeful treatment option for pRCC. Further analysis with a larger number of cases is required to make any conclusion.

In summary, we reported, for the first time, three cases pRCC which were effectively treated with cabozantinib as second- or third-line therapy. The favorable result poses this as a hopeful treatment option for pRCC.

\section{Conflicts of Interest}

Tsunenori Kondo received honoraria from Pfizer, Novartis, and Ono Pharmaceutical. All other Authors have no conflict of interest to declare.

\section{Authors' Contributions}

Hidekazu Tachibana: Acquision of data, analysis and interpretation of data, drafting of the manuscript. Yudai Ishiyama: Acquisition of data. Maki Yoshino: Acquision of data.

Kaori Yamashita: Acquision of data. Daisuke Toki: Supervision. Tsunenori Kondo: Concept and design, analysis and interpretation of data, critical revision of the article for important intellectual content, and supervision.

\section{References}

1 Choueiri TK, Halabi S, Sanford BL, Hahn O, Michaelson MD, Walsh MK, Feldman DR, Olencki T, Picus J, Small EJ, Dakhil $\mathrm{S}$, George DJ and Morris MJ: Cabozantinib versus sunitinib as initial targeted therapy for patients with metastatic renal cell carcinoma of poor or intermediate risk: The Alliance A031203 CABOSUN Trial. J Clin Oncol 35(6): 591-597, 2017. PMID: 28199818. DOI: $10.1200 / J C O .2016 .70 .7398$

2 Choueiri TK, Escudier B, Powles T, Tannir NM, Mainwaring PN, Rini BI, Hammers HJ, Donskov F, Roth BJ, Peltola K, Lee JL, Heng DYC, Schmidinger M, Agarwal N, Sternberg CN, McDermott DF, Aftab DT, Hessel C, Scheffold C, Schwab G, Hutson TE, Pal S, Motzer RJ and METEOR investigators: Cabozantinib versus everolimus in advanced renal cell carcinoma (METEOR): final results from a randomised, openlabel, phase 3 trial. Lancet Oncol 17(7): 917-927, 2016. PMID: 27279544. DOI: 10.1016/S1470-2045(16)30107-3

3 Moch H, Cubilla AL, Humphrey PA, Reuter VE and Ulbright TM: The 2016 WHO classification of tumours of the urinary system and male genital organs-part A: Renal, penile, and testicular tumours. Eur Urol 70(1): 93-105, 2016. PMID: 26935559. DOI: 10.1016/j.eururo.2016.02.029

4 Eisenhauer EA, Therasse P, Bogaerts J, Schwartz LH, Sargent D, Ford R, Dancey J, Arbuck S, Gwyther S, Mooney M, Rubinstein L, Shankar L, Dodd L, Kaplan R, Lacombe D and Verweij J: New response evaluation criteria in solid tumours: revised RECIST guideline (version 1.1). Eur J Cancer 45(2): 228-247, 2009. PMID: 19097774. DOI: 10.1016/j.ejca.2008.10.026

5 Heng DY, Wells JC, Rini BI, Beuselinck B, Lee JL, Knox JJ, Bjarnason GA, Pal SK, Kollmannsberger CK, Yuasa T, Srinivas S, Donskov F, Bamias A, Wood LA, Ernst DS, Agarwal N, Vaishampayan UN, Rha SY, Kim JJ and Choueiri TK: Cytoreductive nephrectomy in patients with synchronous metastases from renal cell carcinoma: results from the International Metastatic Renal Cell Carcinoma Database Consortium. Eur Urol 66(4): 704-710, 2014. PMID: 24931622. DOI: $10.1016 /$ j.eururo.2014.05.034

6 Motzer RJ, Jonasch E, Boyle S, Carlo MI, Manley B, Agarwal N, Alva A, Beckermann K, Choueiri TK, Costello BA, Derweesh IH, Desai A, George S, Gore JL, Haas N, Hancock SL, Kyriakopoulos C, Lam ET, Lau C, Lewis B, Madoff DC, McCreery B, Michaelson MD, Mortazavi A, Nandagopal L, Pierorazio PM, Plimack ER, Ponsky L, Ramalingam S, Shuch B, Smith ZL, Somer B, Sosman J, Dwyer MA and Motter AD: NCCN guidelines insights: kidney cancer, version 1.2021. J Natl Compr Canc Netw 18(9): 1160-1170, 2020. PMID: 32886895. DOI: $10.6004 /$ jncen.2020.0043

7 Pignot G, Elie C, Conquy S, Vieillefond A, Flam T, Zerbib M, Debré B and Amsellem-Ouazana D: Survival analysis of 130 
patients with papillary renal cell carcinoma: prognostic utility of type 1 and type 2 subclassification. Urology 69(2): 230-235, 2007. PMID: 17275070. DOI: 10.1016/j.urology.2006.09.052

8 Motzer RJ, Tannir NM, McDermott DF, Arén Frontera O, Melichar B, Choueiri TK, Plimack ER, Barthélémy P, Porta C, George S, Powles T, Donskov F, Neiman V, Kollmannsberger CK, Salman P, Gurney H, Hawkins R, Ravaud A, Grimm MO, Bracarda S, Barrios CH, Tomita Y, Castellano D, Rini BI, Chen AC, Mekan S, McHenry MB, Wind-Rotolo M, Doan J, Sharma P, Hammers HJ, Escudier B and CheckMate 214 Investigators: Nivolumab plus ipilimumab versus sunitinib in advanced renalcell carcinoma. N Engl J Med 378(14): 1277-1290, 2018. PMID: 29562145. DOI: 10.1056/NEJMoa1712126

9 Tachibana H, Kondo T, Ishihara H, Fukuda H, Yoshida K, Takagi T, Izuka J, Kobayashi $\mathrm{H}$ and Tanabe K: Modest efficacy of nivolumab plus ipilimumab in patients with papillary renal cell carcinoma. Jpn J Clin Oncol, 2020. PMID: 33212488. DOI: 10.1093/jjco/hyaa229

10 Yakes FM, Chen J, Tan J, Yamaguchi K, Shi Y, Yu P, Qian F, Chu F, Bentzien F, Cancilla B, Orf J, You A, Laird AD, Engst S, Lee L, Lesch J, Chou YC and Joly AH: Cabozantinib (XL184), a novel MET and VEGFR2 inhibitor, simultaneously suppresses metastasis, angiogenesis, and tumor growth. Mol Cancer Ther 10(12): 2298-2308, 2011. PMID: 21926191. DOI: 10.1158/15357163.MCT-11-0264
11 Martínez Chanzá N, Xie W, Asim Bilen M, Dzimitrowicz H, Burkart J, Geynisman DM, Balakrishnan A, Bowman IA, Jain R, Stadler W, Zakharia Y, Narayan V, Beuselinck B, McKay RR, Tripathi A, Pachynski R, Hahn AW, Hsu J, Shah SA, Lam ET, Rose TL, Mega AE, Vogelzang N, Harrison MR, Mortazavi A, Plimack ER, Vaishampayan U, Hammers H, George S, Haas N, Agarwal N, Pal SK, Srinivas S, Carneiro BA, Heng DYC, Bosse D, Choueiri TK and Harshman LC: Cabozantinib in advanced non-clear-cell renal cell carcinoma: a multicentre, retrospective, cohort study. Lancet Oncol 20(4): 581-590, 2019. PMID: 30827746. DOI: 10.1016/S1470-2045(18)30907-0

12 Choueiri TK, Heng DYC, Lee JL, Cancel M, Verheijen RB, Mellemgaard A, Ottesen LH, Frigault MM, L'Hernault A, Szijgyarto Z, Signoretti S and Albiges L: Efficacy of savolitinib $v s$. sunitinib in patients with MET-driven papillary renal cell carcinoma: The SAVOIR phase 3 randomized clinical trial. JAMA Oncol 6(8): 1247-1255, 2020. PMID: 32469384. DOI: 10.1001/jamaoncol.2020.2218

Received January 20, 2021

Revised February 10, 2021

Accepted February 14, 2021 